\title{
Multidimensional natal isotopic niches reflect migratory patterns in birds
}

Franzoi $A^{1,2}$, Larsen S. ${ }^{* 3}$, Franceschi P. ${ }^{3}$, Hobson K.A. ${ }^{4}$, Pedrini P. ${ }^{1}$ Camin F. ${ }^{3=}$ \& Bontempo L. ${ }^{3}$

${ }^{1}$ Vertebrate Zoology Department, MUSE - Science Museum, Corso del Lavoro e della Scienza 3, 38122 Trento, TN, Italy

2 Department of Earth and Environmental Sciences, Università degli Studi di Pavia,

15 Via Ferrata 1, 27100 Pavia, Italy

${ }^{3}$ Research and Innovation Centre; Fondazione Edmund Mach, via E. Mach 1, 38010 San Michele all'Adige, Italy.

20 | ${ }^{4}$ Environment and Climate Change Canada, Innovation Blvd., Saskatoon, SK, S7N 3H5, Canada

*Corresponding author: stefano.larsen@fmach.it 


\section{Declarations}

40 Funding. Funding to A.F. was provided by FEM - Fondazione Edmund Mach, Research and Innovation Centre and MUSE - Science Museum of Trento (Accordo di Programma - Provincia Autonoma di Trento).

The Authors declare no conflict of interest.

Data availability. All data used in this study are available in the Dryad repository at: https://doi.org/10.5061/dryad.fn2z34tsk, and will be made publicly available upon acceptance of the manuscript

50 Ethics approval.

All experimental procedures including the permission to trap and hold birds in temporary captivity were authorized by the Autonomous Province of Trento (Autorizzazione del Comitato faunistico provinciale n. 549, $17^{\text {th }}$ February 2009; Autorizzazione del Comitato faunistico provinciale n. 608, $21^{\text {st }}$ November 2011) and

55 were carried out in compliance with the current Italian laws regulating scientific research on animals.

All experimental methods, statistical analyses and results were carried out and reported in accordance with the ARRIVE guidelines on animal research.

60

65 


\section{Abstract}

Naturally occurring stable isotope ratios in animal tissues allow estimation of species trophic position and ecological niche. Measuring multiple isotopes of migratory species along flyway bottlenecks offers the opportunity to sample multiple populations and species whose tissues carry information at continental scales.

We measured $\delta^{2} \mathrm{H}, \delta^{18} \mathrm{O}, \delta^{13} \mathrm{C}, \delta^{15} \mathrm{~N}$ in juvenile feathers of 21 bird species captured at a migratory bottleneck in the Italian Alps.

We examined if trends in individual isotopes reflected known migratory strategies and whether dietary $\left(\delta^{13} \mathrm{C}-\delta^{15} \mathrm{~N}\right)$ and spatially-explicit breeding origin $\left(\delta^{2} \mathrm{H}-\delta^{18} \mathrm{O}\right)$ niche breadth (NB) differed among long-distance trans-Saharan (TS), short-distance (IP) and irruptive (IR) intra-Palearctic migrants, and whether they correlated with reported populations long-term trends.

In both TS and IP groups, species $\delta^{2} \mathrm{H}$ declined with capture date, indicating that 90 northern populations reached the stopover site later in the season, following a Type-I migration strategy. Values of $\delta^{2} \mathrm{H}$ indicated that breeding range of TS migrants extended farther north than IP and IR migrants. The breeding season was longer for IP migrants whose $\delta^{13} \mathrm{C}$ and $\delta^{15} \mathrm{~N}$ values declined and increased, respectively, with time of capture.

95

Average species dietary NB did not differ among migratory groups, but TS migrants displayed wider breeding origin niches, suggesting that long-distant migration is linked to broader ecological niches. Isotope origin NB well reflected species geographic range extent, while dietary NB did not correlate with literature accounts

100 of species' diet. We found no relationship between species breeding NB and population trends in Europe, implying that conditions in the wintering grounds could be more important for the long-term persistence of species.

We demonstrate that isotopic measurements of passerines migrating through a bottleneck represents a unique opportunity to investigate large-scale life-history phenomena relevant to conservation.

110 Keywords: Niche breadth; Migratory bottleneck; trans-Saharan; intra-Palearctic; stable isotopes; Carbon-12, Nitrogen-15, Deuterium, Oxygen-18; Passerines. 


\section{Introduction}

The concept of species' niche is a fundamental pillar of ecological science

120 (Hutchinson, 1957; Chase and Leibold, 2003; Holt, 2009), but remains challenging to quantify empirically. The challenge is particularly acute in the case of long-distance migratory birds due to the seasonal shifts in habitat use and distribution throughout their life-cycles. Yet, habitat conditions in the breeding, stop-over and wintering grounds profoundly influence individual fitness and demography of migratory

125 populations. Long-distance migrants are showing rapid population declines and appear at greater risk of extinction compared to residents (Heldbjerg and Fox, 2008; Evans et al., 2012; Vickery et al., 2014). Therefore, assessing niche parameters and differences among migratory groups can help in understanding the drivers shaping migration strategies and setting conservation actions.

Migratory pathways of multiple species often overlap at stopover sites, which can represent bottlenecks, or passage points, causing high spatio-temporal concentration of many individuals and species from different migratory systems (Heiss, 2013; Buechley et al., 2018; Cardenas-Ortiz et al., 2020). Therefore, estimating niche parameters of individuals intercepted along migratory flyways represents a valuable and cost-effective approach to include multiple species potentially conveying information from large, continental scale, breeding areas (Yohannes et al., 2007; Hobson et al. 2015; Heim et al. 2018; Cardenas-Ortiz et al., 2020).

Ecological niches of species can be approximated using measurements of naturally occurring stable isotope ratios in their tissues. Such "isotopic niches" can be used to empirically quantify the "realised" niche dimensions of species (Bearhop et al., 2004; Newsome et al., 2007), since stable isotope measurements in animal tissues

145 provides a time-integrated average of many feeding events (Hobson 2011). In particular, stable isotope ratios of carbon $\left(\delta^{13} \mathrm{C}\right)$ and nitrogen $\left(\delta^{15} \mathrm{~N}\right)$ have been used to represent the "dietary niche" of an organism because they reflect reliance on 
different primary producers and trophic level, respectively. Although, the dietary niche breadth represented by $\delta^{13} \mathrm{C}$ and $\delta^{15} \mathrm{~N}$ reflects the range in isotope values of dietary inputs in any given area (Hoeninghaus and Zueg 2008, Hette-Tronquar 2019), the isotopic niche space produced is a potentially powerful means of deriving information on diets of migratory birds from broad catchment areas (Newsome et al. 2007, Inger and Bearhop 2008).

Similarly, isotopic values of hydrogen (deuterium; $\delta^{2} H$ ) and oxygen $\left(\delta^{18} \mathrm{O}\right)$ are linked

155 to isotopic values in environmental waters that can show predictable spatial patterns or "isoscapes" at continental scales (Bowen, 2010). Therefore, tissue $\delta^{2} \mathrm{H}$ and $\delta^{18} \mathrm{O}$ values can be used to represent a spatially-explicit "origin niche" of bird species (e.g. Hobson et al. 2004). Although the meteoric relationship predicts a strong correlation between water $\delta^{2} \mathrm{H}$ and $\delta^{18} \mathrm{O}$, this strong relationship tends to break down in

160 consumer tissues within foodwebs due to the fact that oxygen in tissues, unlike hydrogen, can be derived from air as well as diet and drinking water. Moreover, metabolic pathways leading to oxygen incorporation in proteins differ from those involving hydrogen (Vander Zanden et al. 2016, Magozzi et al. 2019). The net result is that the two isotopes tend to be poorly correlated in feathers (Hobson and Koehler

165 2015). As such, values of $\delta^{2} \mathrm{H}$ and $\delta^{18} \mathrm{O}$ could be considered independent in the analyses of feathers and their combined isotopic space would be highly associated with the geographic origins where feathers were grown (Pekarsky et al. 2015).

The use of multiple isotopes in animal tissues has allowed ecologists to estimate 170 trophic niche breadths of different species or individuals in populations (Bearhop et al., 2004; Shipley and Matich, 2020), and the geographic origin of migratory species (Hobson, 1999; Hobson and Wassenaar 2019). These studies have provided insight into trophic relationships in communities (Post, 2002; Abrantes et al., 2014; Wang et al., 2018) as well dietary specialisation (e.g. Bearhop et al. 2004) and migratory 175 pathways of declining bird species (Evans et al., 2012; Steenweg et al., 2017). Due to logistic and economic constraints, most studies measuring both dietary and origin isotope niches have focused on single species or local populations and communities (but see Yohannes et al., 2007; Rader et al., 2017; Ma et al. 2020). However, examining multiple isotope niches at migratory bottlenecks offers the unique 180 opportunity to quantify and compare niche parameters among several bird species that evolved different migratory behaviours. 
In this study, we measured multiple isotopes in the juvenile feathers of approximately 700 individuals from 21 species of European passerines captured during the autumn migration at an Alpine migratory bottleneck over the Italian Alps. Metabolically inert tissues such as feathers show an isotopic composition that reflects the environment during their formation. As a consequence, bird feathers grown in the nest represent "remote carriers" of isotopic information from the breeding grounds (Langin et al., 2007), since many species retain juvenile plumage during subsequent migration and overwintering. In particular, we examined whether dietary $\left(\delta^{13} \mathrm{C}-\delta^{15} \mathrm{~N}\right)$ and origin $\left(\delta^{2} \mathrm{H}-\delta^{18} \mathrm{O}\right)$ niche breadths (NB) differed among species belonging to the transSaharan (TSM), intra-Palearctic (IPM), and irruptive intra-Palearctic (IRM) migratory systems, and the extent to which feather stable isotope values reflected known migratory patterns.

For both TSM and IPM groups, we expected northern populations to reach the autumn Alpine passage later in the season. According to the deuterium precipitation isoscape in the Palearctic (Hobson et al., 2004; Bowen, 2010), this would result in a negative relation between arrival date and $\delta^{2} \mathrm{H}$ for each species, as also observed in

200 Neotropical species adopting a Type-I migration strategy whereby southern populations precede northern ones or as "chain migrants" (Cardenas-Ortiz et al., 2020).

Since IPM species display a longer breeding season (2-3 clutches) compared to 205 TSM (1-2 clutches), we also compared seasonal variation in $\delta^{13} \mathrm{C}$ and $\delta^{15} \mathrm{~N}$ for each species to examine seasonal changes in the availability of main food sources (e.g. larvae to adult insects).

Long-distance migration is thought to have evolved primarily in species able to utilise 210 multiple habitat types (Levey and Stiles, 1992; Cresswell, 2014; Reif et al., 2016), which are encountered en route and in wintering areas. More generally, if migratory connectivity occurs at large scales, it could favour the selection for generalist traits. As such, species migration distance is expected to be directly related to their niche breadth. Although intuitively appealing, this hypothesis has received limited empirical 215 support so far (Cresswell, 2014; Laube et al., 2015; Ponti et al., 2020). Here, we 
specifically examine how migratory distance was related to the origin niche breadth $\left(\delta^{2} \mathrm{H}-\delta^{18} \mathrm{O}\right)$. We test the hypothesis that long-distance migrants such as TSM species, display broader niches than IPM and IRM species.

220 Because the relation between isotope niche measures and other estimates of species niche are still poorly understood (Shipley and Matich, 2020), we also examined whether our measures of dietary and origin isotope niches matched diet and climatic niche breadth derived from the literature and species range maps (Reif et al., 2016). While we expected estimates of spatially-explicit isotope origin niche to accord with species range maps, isotope dietary niche breadth is unlikely to match literature data. This is because diet isotopic dimensions largely depend on the inherent isotopic variance of the resources (Shipley and Matich, 2020), and thus may not adequately reflect the diversity of individual food items in the diet (as reported in the literature), but rather the isotopic diversity of used resources.

Lastly, we assessed whether species isotope niche breadths in the breeding range were related to their long-term population trends as reported in the literature. This is of particular importance for long-distance migrants that show rapid population declines (e.g. Heldbjerg and Fox, 2008; Evans et al., 2012). If species with narrow

235 isotope niches systematically displayed negative population trends, it would indicate that conditions in the breeding grounds are key for the long-term persistence of species.

\section{Methods}

\section{Feather sampling}

Juvenile wing and tail feathers (each grown in the nest; Jenni and Winkler, 2011)

245 from 807 migratory birds belonging to 48 passerine species were sampled at the 'Bocca di Caset' and 'Passo del Brocon' ringing stations (Province of Trento, Italy, $10^{\circ} 41^{\prime} \mathrm{E}, 45^{\circ} 51^{\prime} \mathrm{N}$ and $11^{\circ} 68^{\prime} \mathrm{E}, 46^{\circ} 11^{\prime} \mathrm{N}$, respectively) in the central Italian Alps during autumn migration (from late August to the end of October) from 2010 to 2013. 
Migratory species pass through the Italian Alps at different times during autumn

250 migration (Pedrini et al., 2008). Three migratory groups were considered: longdistance trans-Saharan migrants (TSM), which are fully migratory and leave their breeding ranges to winter in sub-Saharan Africa; short-distance intra-Palaearctic migrants (IPM), which can be fully or partially migratory and which have their breeding and wintering ranges within the Western Palaearctic; irruptive intra-

255 Palaearctic migrants (IRM), which are partial migrants and residents, but show marked invasive and nomadic movements during non-breeding seasons. Date of capture was also recorded for each individual.

\section{Stable isotope analysis}

260 Values of $\delta^{2} \mathrm{H}, \delta^{18} \mathrm{O}, \delta^{13} \mathrm{C}, \delta^{15} \mathrm{~N}$ were measured for each individual feather. It was possible to determine all four isotope ratios in the majority of individuals. Feathers were first washed in a solvent mixture (diethyl ether-methanol 2:1) prior to analysis (Bontempo et al., 2014). Simultaneous determination of $\delta^{13} \mathrm{C}$ and $\delta^{15} \mathrm{~N}$ (i.e. in the same run) was accomplished using a Vario Isotope Cube isotope ratio mass spectrometer (Elementar, Germany). The $\delta^{2} \mathrm{H}$ and $\delta^{18} \mathrm{O}$ values were determined through pyrolysis combustion using a TC/EA (Thermo Finnigan, Bremen, Germany) interfaced with a Delta Plus XP (Thermo Finnigan, Bremen, Germany) continuousflow isotope-ratio mass spectrometer. Pyrolysis was carried out at $1450^{\circ} \mathrm{C}$ in a glassy carbon column. The helium carrier flow was $110 \mathrm{ml} / \mathrm{min}$, the GC column was

270 a $1.2 \mathrm{~m}$ long molecular sieve $5 \mathrm{~A}$, at $110^{\circ} \mathrm{C}$. Isotope ratios were expressed in $\delta$ notation against V-PDB (Vienna-Pee Dee Belemnite) for $\delta^{13} \mathrm{C}$, Air for $\delta^{15} \mathrm{~N}, \mathrm{~V}-\mathrm{SMOW}$ (Vienna-Standard Mean Ocean Water) for $\delta^{2} \mathrm{H}$ and $\delta^{18} \mathrm{O}$. Isotopic values of $\delta^{2} \mathrm{H}$ were calculated using the comparative equilibration approach (Wassenaar and Hobson, $2003,2006)$. based on the keratin standards CBS $\left(\delta^{2} \mathrm{H}-197 \% 0, \delta^{18} \mathrm{O}=+3.8 \%\right.$ ) and

$275 \mathrm{KHS}\left(-54.1 \%\right.$ o, $\delta^{18} \mathrm{O}=+20.3 \%$ ). Values of $\delta^{13} \mathrm{C}$ and $\delta^{15} \mathrm{~N}$ were calculated against working in-house standards (casein and wheat), which were themselves calibrated against international reference materials using multi-point normalisation: fuel oil NBS-22 (IAEA International Atomic Energy Agency, Vienna, Austria; -30.03\%o) and sugar IAEA-CH-6 (- $10.45 \%$ ) for $\delta^{13} \mathrm{C}$, L-glutamic acid USGS 40 (-26.39\%o and -4.5

$280 \%$ for $\delta^{13} \mathrm{C}$ and $\left.\delta^{15} \mathrm{~N}\right)$, hair USGS $42\left(\delta^{15} \mathrm{~N}=+8.05 \%\right.$ and $\delta^{13} \mathrm{C}=-21.09 \%$ ) and USGS $43\left(\delta^{15} \mathrm{~N}=+8.44 \%\right.$ and $\delta^{13} \mathrm{C}=-21.28 \%$ ) for ${ }^{13} \mathrm{C} /{ }^{12} \mathrm{C}$ and ${ }^{15} \mathrm{~N} /{ }^{14} \mathrm{~N}$. Values of $\delta^{13} \mathrm{C}$ were expressed versus $\mathrm{V}-\mathrm{PDB}$ on a scale normalised against the two reference 
materials LSVEC (-46.6\%) and NBS 19 (+1.95\%) (Brand et al., 2014). Values of $\delta^{15} \mathrm{~N}$ were expressed versus Air-N2 on a scale normalised using the two reference materials IAEA-N-1 and USGS32, with consensus values of $+0.4 \%$ and $+180 \%$ (Brand et al., 2014). Method uncertainty (calculated as one standard deviation) was $0.1 \%$ for $\delta^{13} \mathrm{C}, 0.2 \%$ for $\delta^{15} \mathrm{~N}, 0.3 \%$ for $\delta^{18} \mathrm{O}$ and $2 \%$ for $\delta^{2} \mathrm{H}$.

\section{Data analysis}

We gathered information on migratory behaviour and distance for each bird species from the literature (Del Hoyo et al., 2013). Migration distance was calculated as the distance between the centroids of the breeding and wintering areas. Specifically, distance was estimated as the mean of the two latitudes during breeding minus the

295 mean of the two latitudes during winter (Møller et al., 2008).

To compare empirical estimates of dietary and origin isotopic niche breadth with literature data, we used recently published measures of diet specialisation and climate niche breadth that were derived from literature data and breeding range maps of European birds (Reif et al. 2016). Diet specialisation was expressed as the

300 coefficient of variation in the presence/absence of eight food types in the diet of each species (foliage, fruit, grain, insects, other invertebrates, terrestrial vertebrates, water vertebrates, carrion). Climate niche breadth was measured by overlying the breeding range map of each species to climatic data and calculating the covered temperature range (see Reif et al. 2016 for details).

305 Information on long-term population trends for each species at the European scale was gathered from the PanEuropean Common Bird Monitoring Scheme (PECBMS) (https://pecbms.info/trends-and-indicators/species-trends/).

Dietary isotopic niche breadth (NB) was expressed as the Bayesian Standard Ellipse

310 Area corrected for small sample size (SEAc) using the isotopic space defined by $\delta^{13} \mathrm{C}-\delta^{15} \mathrm{~N}$. Similarly, spatially-explicit origin NB was expressed as SEAc from the $\delta^{2} \mathrm{H}-\delta^{18} \mathrm{O}$ space. The SIBER R-package was used for these calculations (Jackson et al., 2011; Rader et al., 2017). 
315 Differences in NB among migratory groups were examined using generalised least squares (GLS) allowing the variance to differ among groups (with varIdent function in R). Seasonal trends in $\delta^{2} \mathrm{H}, \delta^{13} \mathrm{C}$ and $\delta^{15} \mathrm{~N}$ within each migratory group were assessed using linear mixed-effect models including species as random factor to account for different isotope values and trends across species. We used the Ime

320 function in $\mathrm{R}$ allowing both intercept and slope to differ among species. To examine if origin NB was related to migration distance, we used GLS to regress the mean NB values for each species (across all measured individuals) against the estimated migration distance.

Although migration timing can vary within species depending on age and sex, we were not able to consistently record this information from our samples to model it statistically.

\section{Results}

Over the four years of sampling, more than 800 individuals of 48 passerine species were captured. After excluding species with less than 15 individuals, we included isotope data from 715 individuals of 21 species (Tab. S1). These belonged to the trans-Saharan (7 species; 241 individuals), intra-Palearctic (11 species; 335 individuals) and irruptive (3 species; 91 individuals) migratory systems. Overall distribution of species over isotope space is shown in Fig. 1 and 2. Migratory phenology of each species during the autumn passage is shown in Fig.S1 (Supplementary Material), where the temporal patterns in the number of species captured is also shown.

Seasonal changes in $\delta^{2} \mathrm{H}$ (reflecting species breeding latitude) supported the hypothesis that both TSM and IPM groups display a Type-I (chain) migration, whereby northern populations (with lower $\delta^{2} \mathrm{H}$ values) reached the Alpine passage later in the season (Fig.3). This pattern appeared consistent among species in each group, with a significant effect of capture day in the Ime model $(p<0.01$ for both groups). Mean $\delta^{2} \mathrm{H}$ values were evidently lower for TSM, indicating that species in 
this migratory group tend to breed at higher latitudes than IPM. No seasonal trend in $\delta^{2} \mathrm{H}$ was observed in IRM species.

A seasonal trend in $\delta^{15} \mathrm{~N}$ was evident for IPM and IRM species with a positive effect of capture day (Ime p<0.01). This trend was not observed in TSM, which displayed slightly higher mean $\delta^{15} \mathrm{~N}$ values (Fig.3). Similarly, a significant negative trend in $\delta^{13} \mathrm{C}$ was observed in IPM ( $p<0.01)$, which was not significant in either TSM and IRM species. Fig. 3 also shows that most TSM species reached the capture site by day 280, whereas the season appeared longer for IPM and IRM. The difference in phenology is also clear from Fig.S1.

Average species dietary isotopic NB did not differ significantly among migratory groups (Fig.4). Conversely, the average isotopic origin niche was significantly broader for TSM, about 30\% broader than IPM (GLS model; $p=0.03$ ). However, there

360 was relatively large variation in origin NB within TSM. IRM displayed a much narrower origin NB (Fig.4). Excluding the apparent outliers from the analysis of dietary NB $\left(\delta^{13} \mathrm{C}-\delta^{15} \mathrm{~N}\right.$; Regulus regulus and Delichon urbicum), provided qualitatively similar results.

In addition, migration distance was related to the breadth of species origin niche, 365 although there was considerable variation at larger distances (Fig. 5; GLS; p=0.01). No relationship was observed between dietary isotopic NB and migration distance (Fig.S2).

We compared our estimates of species dietary and origin isotopic niche with those recently derived from species distributional data. We found that origin NB well matched measures from range maps (Fig. 6), with a positive linear correlation $(p=0.02)$. In addition, climate niche breadth derived from range maps well reflected the upper distribution of the empirical isotope origin niche. This is evident from the significant quantile regression at $q=0.8(p<0.01)$. Conversely, the dietary isotopic NB was not related to diet specialisation, as derived from the literature.

Finally, we appraised whether long-term population trends were related to the empirical isotope niches. Neither dietary not origin isotopic niche breadth were related to species population trends as reported in the PECBMS portal (Fig.S3). 


\section{Discussion}

We used juvenile feathers of multiple bird species intercepted along an autumn migratory flyway as 'remote carriers' of isotope niche information from Western Palearctic breeding areas. This allowed quantifying niche parameters from species

390 that evolved different migratory strategies. In addition, despite potential confounding factors related to variance in local isotopic baselines, including individuals from different populations and communities allowed the estimation of species niches that were less influenced by local biotic interactions (e.g. competition), and likely more representative of the realised niche dimensions of the species.

395

Our results generally supported our initial hypotheses, but also revealed a poor association between isotope niche dimensions and literature-derived niche parameters and long-term population trends.

400 Seasonal trends in feather $\delta^{2} \mathrm{H}$ indicated that individuals breeding at higher latitudes (displaying lower $\delta^{2} \mathrm{H}$ values) reached the sampling locations later in the season, with patterns that appeared consistent among species and across the two major migratory groups (TSM, IPM). This type of migration, often called Type I (as opposed to Type-II, whereby northern populations leap-frog southern populations during

405 migration), has also been observed across a range of Nearctic-Neotropical migrants (Dunn et al. 2006, Cardenas-Ortiz et al., 2020), and appears common in AfroPalearctic migrants as well (Briedis et al., 2016, 2020). Different migration timing of conspecific populations contributes to limit competition among individuals and likely occurs at the species level too. Assessing temporal segregation in the use of

410 migratory stopover helps identify the species most likely to co-occur and compete locally for resources. In our study site, a few species showed complete segregation (Fig.S1), but high overlap was otherwise evident with up to nine migratory species captured in a single day. Bottlenecks can indeed concentrate large numbers of 
individuals and species during a short period, which not only heightens intra- and 415 inter-specific competition, but also increases vulnerability to localised events and disturbance (Cardenas-Ortiz et al., 2020). The identification and conservation of migratory stopover and bottlenecks are therefore key for the persistence of many declining populations (Heiss, 2013; Buechley et al., 2018; Cardenas-Ortiz et al., $2020)$.

Seasonal trends observed in both $\delta^{15} \mathrm{~N}$ and $\delta^{13} \mathrm{C}$ in IPM is indicative of possible shifts in the availability or quality of resources for these species. However, these patterns could be explained by different non-mutually exclusive mechanisms. For instance, seasonally rising values of $\delta^{15} \mathrm{~N}$ could be associated with the increased availability of 425 adult insects (as opposed to larvae or other arthropods with lower $\delta^{15} \mathrm{~N}$ values) as the longer breeding season of IPM progresses. Conversely, the shorter season of TSM and their strictly insectivorous diet would result in more seasonally stable $\delta^{15} \mathrm{~N}$ values. Alternatively, a geographic explanation is also plausible. The lower latitude breeding range of IPM, as well as IRM (compared to TSM), implies that early

430 captures were dominated by individuals from the Alpine/central-Europe/Carpathian areas at high elevations. This could be associated with higher $\delta^{13} \mathrm{C}$ (Hobson et al., 2004) and possibly with lower $\delta^{15} \mathrm{~N}$ due to lower precipitation compared to northern Europe (Cortesi et al., 2012). It is also possible that the extent of anthropogenic nitrogen input from agriculture is lower in mountainous regions, which could contribute to lower $\delta^{15} \mathrm{~N}$ in early captures. It is known, in fact, that anthropogenic sources such as fertilisers can alter and mostly increase nitrogen isotopic baseline values (Shipley and Matich, 2020).

We found that species breeding origin niche was, on average, broader in long440 distance trans-Saharan compared to intra-Palearctic migrants. Long-distance migration is generally thought to have evolved from ancestor species with broad habitat niches: individuals able to exploit a wider range of conditions during migration or at wintering grounds should be selectively advantaged over more specialised ones (Levey and Stiles, 1992; Cresswell, 2014; Reif et al., 2016). Empirical support

445 for this hypothesis is limited (Salewski et al., 2003; Jones et al., 2010; Laube et al., 2015), and our data thus provide some additional evidence. However, the link between niche breadth and migration patterns remains unclear, with some evidence 
suggesting the opposite view that narrower habitat or diet niche may have favoured long-distance migrations (e.g. Brändle et al., 2002), because specialists are forced to leave an area when conditions become unfavourable or resources scarce. Yet, our data do not show any correlation between migration distance and dietary niche breadth, providing no support for this alternative hypothesis. It has to be kept in mind, however, that our estimates of ecological niches reflect the breeding range of species (i.e. isotopes from juvenile feathers grown at nest), and the inclusion of

455 information from wintering grounds would have provided a more complete and likely different picture. This would require measuring isotope ratios in body tissues with different turnover or growth rates (Hahn et al., 2013), or collecting feathers grown in winter (Steenweg et al., 2017). However, for most passerine species, information on wintering locations is still limited, especially for the Afro-Palearctic migration system

460 (Finch et al., 2017; Somveille et al., 2019). Similarly, the extent to which migratory species track their climate and habitat niche between breeding and wintering grounds is poorly understood and likely to vary among species (Somveille et al., 2019; Ponti et al., 2020). Most assessments of seasonal niche shifts during migration relied on large-scale climatic and land-use data (Gómez et al., 2016; Zurell et al.,

465 2018; Ponti et al., 2020), while those employing tissues isotopes are rare and mostly focussed on a few key species to appraise migratory connectivity (Rubenstein, 2002; Yohannes et al., 2007; Hahn et al., 2013). Therefore, it is difficult to evaluate whether and to what extent our estimates of isotope niche breadth would have differed had we included wintering isotope signals.

We used recently published data from Reif et al. (2016) to examine the extent to which isotope niches from our sampled populations reflected diet specialisation and climate niche breadth reported at the species level. As expected, dietary isotopic niche did not match the breadth or diversity of consumed food items reported in the

475 literature. This further supports the notion that the breadth of dietary isotope niche reflects the isotopic variance of the resources and should not be considered synonymous of species diet (Shipley \& Matich, 2020). Conversely, estimates of spatially-explicit breeding origin niche correlated significantly, albeit weakly, with literature data. In particular, measures of climatic niche from range maps appeared 480 to better predict the upper distribution (quantile: 0.8 ) of our isotope niche, rather than its central response. A possible interpretation is that niche estimates derived from 
range maps necessarily reflect the maximum expected value for a given population. In other words, if we assume that a correlation exists between spatially-explicit origin niche inferred from isotope and range maps, any sampled populations should display isotope niches that are either equal or narrower than those derived from species full range maps. This provides additional evidence that species bi-dimensional $\delta^{2} \mathrm{H}-\delta^{18} \mathrm{O}$ isotope space is a good proxy of their geographic and climatic niche dimensions (e.g. Rader et al., 2017).

490 Among the key motivations for appraising niche requirements of migratory species, is that their populations appear to be declining more rapidly than residents (Sanderson et al., 2006; Heldbjerg and Fox, 2008; Evans et al., 2012; Ockendon et al., 2012). The mechanisms underpinning these trends are still unclear and we examined whether narrow isotope breeding niches were associated with stronger

495 population declines. We found no correlation between either dietary or origin breeding niche and long-term population trends as reported in the Pan European Common Bird Monitoring Scheme. This is not surprising as there is increasing evidence that environmental conditions and dynamics in non-breeding areas are key for the long-term persistence of populations (Keller and Yahner, 2006; Sanderson et 500 al., 2006; Morrison et al., 2013). In particular, habitat change and degradation in tropical wintering areas appear to be a major cause of decline in migrant species (Bennett et al., 2018; Şekercioğlu et al., 2019). This further emphasises that quantifying both breeding and wintering niche parameters would provide insight not only on basic ecological questions such as the degree of niche tracking, but also on conservation requirements of long distance migrants (Hahn et al., 2013).

We used multiple stable isotopes to quantify and compare ecological niche parameters between short- and long-distance migrants. We showed that autumn migratory bottlenecks, such "Bocca di Caset" and "Passo del Brocon" in the Italian

510 Alps, not only represent important stopovers for many migrants of the Western flyway (Briedis et al., 2020), but also strategic natural laboratories to examine migratory patterns across multiple species.

Our results illustrate that long-distance trans-Saharan migrants, mostly breeding at higher latitudes than intra-Palearctic migrants, reach the migratory stop-over sooner.

515 This is in line with the notion that early departure allows trans-Saharan migrants to 
reach the Sahel zone at the peak of vegetation greenness, when feeding conditions are optimal (Newton, 2007; Thorup et al., 2017). Moreover, in both migratory groups, the onset of breeding for northern populations appeared delayed, likely due to climatic constraints, so that the timing of migration was proportionally shifted later in

520 the season. The delayed timing of northern populations can apparently carry over to the entire annual cycle (Briedis et al., 2016), and likely contributes to limit intraspecific competition. This type of migration pattern appears fairly common in many Neartic-Neotropical migrants too (Dunn et al. 2006; Cardenas-Ortiz et al., 2020). Our data also provide some support to the hypothesis that broad ecological niches are linked to long-distance migration, although this was only evident for the breeding origin niche dimensions, and requires further testing.

The use of multiple isotope ratios in animal tissues has allowed the quantification of both dietary and spatially-explicit niche aspects (Shipley and Matich, 2020).

530 However, the relation between the isotopic ecological niche and other descriptors of species niche (e.g. based on feeding habits, distribution patterns), or conservation status remains vague (Rader et al., 2017; Shipley and Matich, 2020). Here, we found that origin isotopic niche reflected the climatic range extent of the species, illustrating how $\delta^{2} \mathrm{H}$ and $\delta^{18} \mathrm{O}$ measurements can provide insight into origins related to bio-

535 climatic and geographic isotopic patterns. However, the breadth of isotope niches was not able to explain the long-term population trends of the species at the European scale. Appraisal of the complete multi-seasonal niche dimension of longdistance migrants is therefore needed to link ecological information to conservation actions for these declining species.

\section{Acknowledgements}

Funding to A.F. was provided by FEM - Fondazione Edmund Mach, Research and Innovation Centre and MUSE - Science Museum of Trento (Accordo di Programma

545 - Provincia Autonoma di Trento). This study complies with the current Italian laws regulating scientific research on animals. The authors gratefully acknowledge $G$. Bogliani and S. Tenan, for their suggestions in the early phase of this study, and A. Tonon and L. Ziller for the analytical support, S. Noselli, F. Rizzolli and F. Rossi for field work. 


\section{References}

555

Abrantes, K. G., Barnett, A., and Bouillon, S. (2014). Stable isotope-based community metrics as a tool to identify patterns in food web structure in east African estuaries. Funct. Ecol. 28, 270-282. doi:10.1111/1365-2435.12155.

Bearhop, S., Adams, C. E., Waldron, S., Fuller, R. A., and Macleod, H. (2004). Determining trophic niche width: a novel approach using stable isotope analysis: Stable isotopes as measures of niche width. J. Anim. Ecol. 73, 1007-1012. doi:10.1111/j.0021-8790.2004.00861.x.

Bennett, R. E., Leuenberger, W., Leja, B. B. B., Cáceres, A. S., Johnson, K., and Larkin, J. (2018). Conservation of Neotropical migratory birds in tropical hardwood and oil palm plantations. PLOS ONE 13, e0210293. doi:10.1371/journal.pone.0210293.

Bontempo, L., Ceppa, F., Ziller, L., Pedrini, P., Hobson, K. A., Wassenaar, L. I., et al. (2014). Comparison of methods for stable isotope ratio $(\delta 13 \mathrm{C}, \delta 15 \mathrm{~N}, \delta 2 \mathrm{H}$, ठ180) measurements of feathers. Methods Ecol. Evol. 5, 363-371. doi:10.1111/2041-210X.12165.

Bowen, G. J. (2010). Isoscapes: Spatial Pattern in Isotopic Biogeochemistry. Annu. Rev. Earth Planet. Sci. 38, 161-187. doi:10.1146/annurev-earth-040809152429.

Brand, W. A., Coplen, T. B., Vogl, J., Rosner, M., and Prohaska, T. (2014). Assessment of international reference materials for isotope-ratio analysis (IUPAC Technical Report). Pure Appl. Chem. 86, 425-467. doi:10.1515/pac2013-1023.

Brändle, M., Prinzing, A., Pfeifer, R., and Brandl, R. (2002). Dietary niche breadth for Central European birds: correlations with species-specific traits. 16.

Briedis, M., Bauer, S., Adamík, P., Alves, J. A., Costa, J. S., Emmenegger, T., et al. (2020). Broad-scale patterns of the Afro-Palaearctic landbird migration. Glob. Ecol. Biogeogr. 29, 722-735. doi:10.1111/geb.13063.

Briedis, M., Hahn, S., Gustafsson, L., Henshaw, I., Träff, J., Král, M., et al. (2016). Breeding latitude leads to different temporal but not spatial organization of the annual cycle in a long-distance migrant. J. Avian Biol. 47, 743-748. doi:10.1111/jav.01002.

Brown, J. (1984). On the Relationship between Abundance and Distribution of Species. Am. Nat. 124. doi/10.1086/284267.

Buechley, E. R., Oppel, S., Beatty, W. S., Nikolov, S. C., Dobrev, V., Arkumarev, V., et al. (2018). Identifying critical migratory bottlenecks and high-use areas for an endangered migratory soaring bird across three continents. J. Avian Biol. 49, e01629. doi:10.1111/jav.01629.

Cardenas-Ortiz, L., Bayly, N. J., Kardynal, K. J., and Hobson, K. A. (2020). Defining catchment origins of a geographical bottleneck: Implications of population mixing and phenological overlap for the conservation of Neotropical migratory birds. The Condor 122, duaa004. doi:10.1093/condor/duaa004.

Chase, J. M., and Leibold, M. A. (2003). Ecological niches. Linking classical and 
contemporary approaches. University of Chicago Press.

Clark, I. and P. Fritz. 1997. Environmental Isotopes in Hydrogeology. CRC Press, London.

600 Cortesi, N., Gonzalez-Hidalgo, J. C., Brunetti, M., and Martin-Vide, J. (2012). Daily precipitation concentration across Europe 1971-2010. Nat. Hazards Earth Syst. Sci. 12, 2799-2810. doi:10.5194/nhess-12-2799-2012.

Cresswell, W. (2014). Migratory connectivity of Palaearctic-African migratory birds and their responses to environmental change: the serial residency hypothesis. Ibis 156, 493-510. doi:10.1111/ibi.12168.

Del Hoyo, J., Elliott, A., Sargatal, J., and Christie, D. (2013). Handbook of the Birds of the World (16-Volume Set + Special Volume). Lynx Edicions Available at: https://www.nhbs.com/handbook-of-the-birds-of-the-world-16-volume-setspecial-volume-book [Accessed October 22, 2020].

Dunn, E.H., K. A. Hobson, L. I. Wassenaar, D. Hussell, and M. L. Allen. 2006. Identification of summer origins of songbirds migrating through southern Canada in Autumn. Avian Conservation and Ecology 1:4 doi: 10.5751/ACE00048-010204

Evans, K. L., Newton, J., Mallord, J. W., and Markman, S. (2012). Stable Isotope Analysis Provides New Information on Winter Habitat Use of Declining Avian Migrants That Is Relevant to Their Conservation. PLoS ONE 7, e34542. doi:10.1371/journal.pone.0034542.

Finch, T., Butler, S. J., Franco, A. M. A., and Cresswell, W. (2017). Low migratory connectivity is common in long-distance migrant birds. J. Anim. Ecol. 86, 662673. doi:10.1111/1365-2656.12635.

Gómez, C., Tenorio, E. A., Montoya, P., and Cadena, C. D. (2016). Niche-tracking migrants and niche-switching residents: evolution of climatic niches in New World warblers (Parulidae). Proc. R. Soc. B Biol. Sci. 283, 20152458. doi:10.1098/rspb.2015.2458.

625 Hahn, S., Amrhein, V., Zehtindijev, P., and Liechti, F. (2013). Strong migratory connectivity and seasonally shifting isotopic niches in geographically separated populations of a long-distance migrating songbird. Oecologia 173, 1217-1225. doi:10.1007/s00442-013-2726-4.

Heiss, M. (2013). The Importance of Besh Barmag Bottleneck (Azerbaijan) for Eurasian Migrant Birds. Acta Ornithol. 48, 151-164. doi:10.3161/000164513X678900.

Heldbjerg, H., and Fox, T. (A D. ) (2008). Long-term population declines in Danish trans-Saharan migrant birds. Bird Study 55, 267-279. doi:10.1080/00063650809461532.

635 Hette-Tronquart, N. 2019. Isotopic niche is not equal to trophic niche. Ecology Letters 22: 1987-1989. doi: https://doi.org/10.1111/ele.13218

Hobson, K. A. (1999). Tracing origins and migration of wildlife using stable isotopes: a review. Oecologia 120, 314-326. doi:10.1007/s004420050865.

Hobson, K.A. 2011. Isotopic Ornithology: a perspective. Journal of Ornithology 152:49-66.doi: https://doi.org/10.1007/s10336-011-0653-x

Hobson, Keith A. and Geoff Koehler. 2015. On the use of stable oxygen isotope $\left(\delta^{18} \mathrm{O}\right)$ measurements for tracking avian movements in North America. Ecology and Evolution 5:799-806. https://doi.org/10.1002/ece3.1383

Hobson, K.A. and Wassenaar, LI (Eds) 2019. Tracking Animal Migration using Stable Isotopes, Second Edition.. Academic Press, London, 253 pp.

Hobson, K. A., Bowen, G. J., Wassenaar, L. I., Ferrand, Y., and Lormee, H. (2004). 
Using stable hydrogen and oxygen isotope measurements of feathers to infer geographical origins of migrating European birds. Oecologia 141, 477-488. doi:10.1007/s00442-004-1671-7.

650 Hobson, K.A., S. Van Wilgenburg, E. Dunn, D. Hussel, P. Taylor, and D. Collister. 2015. Predicting origins of passerines migrating through Canadian migration monitoring stations using stable-hydrogen isotope analyses of feathers: A new tool for bird conservation. Avian Conservation and Ecology 10: 3. http://dx.doi.org/10.5751/ACE-00719-100103.

655 Hoeininghaus, D.J. and S.C. Zeug. 2008. Can stable isotope ratios provide for community-wide measures of trophic structure? Comment. Ecology 89: 23532357.https://doi.org/10.1890/07-1143.1

Holt, R. D. (2009). Bringing the Hutchinsonian niche into the 21st century: Ecological and evolutionary perspectives. Proc. Natl. Acad. Sci. 106, 19659-19665. doi:10.1073/pnas.0905137106.

Hutchinson, G. E. (1957). Concluding Remarks. Cold Spring Harb. Symp. Quant. Biol. 22, 415-427. doi:10.1101/SQB.1957.022.01.039.

Inger, R., and Bearhop, S. (2008). Applications of stable isotope analyses to avian ecology: Avian stable isotope analysis. Ibis 150, 447-461. doi:10.1111/j.1474919X.2008.00839.x.

Jackson, A. L., Inger, R., Parnell, A. C., and Bearhop, S. (2011). Comparing isotopic niche widths among and within communities: SIBER - Stable Isotope Bayesian Ellipses in R: Bayesian isotopic niche metrics. J. Anim. Ecol. 80, 595-602. doi:10.1111/j.1365-2656.2011.01806.x.

Jenni, L., and Winkler, R. (2011). Moult and Ageing of European Passerines. Academic Press.

Jones, P., Salewski, V., Vickery, J., and Mapaure, I. (2010). Habitat use and densities of co-existing migrant Willow Warblers Phylloscopus trochilus and resident eremomelas Eremomela spp. in Zimbabwe. Bird Study 57, 44-55. doi:10.1080/00063650903071401.

Keller, G. S., and Yahner, R. H. (2006). Declines of Migratory Songbirds: Evidence for Wintering-Ground Causes. Northeast. Nat. 13, 83-92.

Langin, K. M., Reudink, M. W., Marra, P. P., Norris, D. R., Kyser, T. K., and Ratcliffe, L. M. (2007). Hydrogen isotopic variation in migratory bird tissues of known origin: implications for geographic assignment. Oecologia 152, 449-457. doi:10.1007/s00442-007-0669-3.

Laube, I., Graham, C. H., and Böhning-Gaese, K. (2015). Niche availability in space and time: migration in Sylvia warblers. J. Biogeogr. 42, 1896-1906. doi:10.1111/jbi.12565.

Levey, D. J., and Stiles, F. G. (1992). Evolutionary Precursors of Long-Distance Migration: Resource Availability and Movement Patterns in Neotropical Landbirds. Am. Nat. 140, 447-476. doi:10.1086/285421.

Ma Y., K.A. Hobson, C. Guglielmo, K. Kardynal and B. Branfireun. 2020. Inferring spatial patterns of mercury burden in migratory boreal songbirds: Combining feather mercury and stable isotope $\left(\delta^{2} \mathrm{H}\right)$ measurements. Science of the Total Environment, in press.

Magozzi, Sarah, Hannah B. Vander Zanden, Michael B. Wunder, and Gabriel J. Bowen.2019. Mechanistic model predicts tissue-environment relationships and trophic shifts in animal hydrogen and oxygen isotope ratios. Oecologia. https://doi.org/10.1007/s00442-019-04532-8.

Møller, A. P., Rubolini, D., and Lehikoinen, E. (2008). Populations of migratory bird 
species that did not show a phenological response to climate change are declining. Proc. Natl. Acad. Sci. 105, 16195-16200.

doi:10.1073/pnas.0803825105.

700

Morrison, C. A., Robinson, R. A., Clark, J. A., Risely, K., and Gill, J. A. (2013). Recent population declines in Afro-Palaearctic migratory birds: the influence of breeding and non-breeding seasons. Divers. Distrib. 19, 1051-1058. doi:10.1111/ddi.12084.

Newsome, S. D., Martinez del Rio, C., Bearhop, S., and Phillips, D. L. (2007). A niche for isotopic ecology. Front. Ecol. Environ. 5, 429-436. doi:10.1890/060150.1.

Newton, I. (2007). The Migration Ecology of Birds. Academic Press.

Ockendon, N., Hewson, C. M., Johnston, A., and Atkinson, P. W. (2012). Declines in British-breeding populations of Afro-Palaearctic migrant birds are linked to bioclimatic wintering zone in Africa, possibly via constraints on arrival time advancement. Bird Study 59, 111-125. doi:10.1080/00063657.2011.645798.

Pedrini, P., Rossi, F., and Spina, F. (2008). Le Alpi italiane quale barriera ecologica nel corso della migrazione post-riproduttiva attraverso l'Europa. Risultati generali della prima fase del Progetto Alpi (1997-2002). Biol. E Conserv. Della Fauna 116, 1-336.

Pekarsky, S., A. Angert, B. Haese, M. Werner, K.A. Hobson, and R.Nathan. 2015. Enriching the isotopic toolbox for migratory connectivity analysis: A new approach for migratory species breeding in remote or unexplored areas. Diversity and Distributions DOI: 10.1111/ddi.12306.

Ponti, R., Arcones, A., Ferrer, X., and Vieites, D. R. (2020). Seasonal climatic niches diverge in migratory birds. Ibis 162, 318-330. doi:10.1111/ibi.12784.

Post, D.M. (2002). Using stable isotopes to estimate trophic position: models, methods and assumptions. Ecology 83 (3), 703-718.https://doi.org/10.1890/0012-9658(2002)083[0703:USITET]2.0.CO;2

Rader, J. A., Newsome, S. D., Sabat, P., Chesser, R. T., Dillon, M. E., and Martínez del Rio, C. (2017). Isotopic niches support the resource breadth hypothesis. J. Anim. Ecol. 86, 405-413. doi:10.1111/1365-2656.12629.

Reif, J., Hořák, D., Krištín, A., Kopsová, L., and Devictor, V. (2016). Linking habitat specialization with species' traits in European birds. Oikos 125, 405-413. doi:10.1111/oik.02276.

Rubenstein, D. R. (2002). Linking Breeding and Wintering Ranges of a Migratory Songbird Using Stable Isotopes. Science 295, 1062-1065. doi:10.1126/science.1067124.

Salewski, V., Bairlein, F., and Leisler, B. (2003). Niche partitioning of two Palearctic passerine migrants with Afrotropical residents in their West African winter quarters. Behav. Ecol. 14, 493-502. doi:10.1093/beheco/arg021.

Sanderson, F. J., Donald, P. F., Pain, D. J., Burfield, I. J., and van Bommel, F. P. J. (2006). Long-term population declines in Afro-Palearctic migrant birds. Biol. Conserv. 131, 93-105. doi:10.1016/j.biocon.2006.02.008.

Şekercioğlu, Ç. H., Mendenhall, C. D., Oviedo-Brenes, F., Horns, J. J., Ehrlich, P. R., and Daily, G. C. (2019). Long-term declines in bird populations in tropical agricultural countryside. Proc. Natl. Acad. Sci. 116, 9903-9912. doi:10.1073/pnas.1802732116.

Shipley, O. N., and Matich, P. (2020). Studying animal niches using bulk stable isotope ratios: an updated synthesis. Oecologia 193, 27-51. doi:10.1007/s00442-020-04654-4. 
Soberón, J. (2007). Grinnellian and Eltonian niches and geographic distributions of species. Ecol. Lett. 10, 1115-1123. doi:10.1111/j.1461-0248.2007.01107.x.

Soberon, J., and Nakamura, M. (2009). Niches and distributional areas: Concepts, methods, and assumptions. Proc. Natl. Acad. Sci. 106, 19644-19650. doi:10.1073/pnas.0901637106.

Somveille, M., Manica, A., and Rodrigues, A. S. L. (2019). Where the wild birds go: explaining the differences in migratory destinations across terrestrial bird species. Ecography 42, 225-236. doi:10.1111/ecog.03531.

Steenweg, R. J., Crossin, G. T., Kyser, T. K., Merkel, F. R., Gilchrist, H. G., Hennin, H. L., et al. (2017). Stable isotopes can be used to infer the overwintering locations of prebreeding marine birds in the Canadian Arctic. Ecol. Evol. 7 , 8742-8752. doi:10.1002/ece3.3410.

Thorup, K., Tøttrup, A. P., Willemoes, M., Klaassen, R. H. G., Strandberg, R., Vega, M. L., et al. (2017). Resource tracking within and across continents in longdistance bird migrants. Sci. Adv. 3, e1601360. doi:10.1126/sciadv.1601360.

Vander Zanden, Hannah B., David X. Soto, Gabriel J. Bowen, and Keith A. Hobson.2016. Expanding the isotopic toolbox: Applications of hydrogen and oxygen stable isotope ratios to food web studies. Frontiers in Ecology and Evolution 4:20. doi: 10.3389/fevo.2016.00020.

Vickery, J. A., Ewing, S. R., Smith, K. W., Pain, D. J., Bairlein, F., Škorpilová, J., et al. (2014). The decline of Afro-Palaearctic migrants and an assessment of potential causes. Ibis 156, 1-22. doi:10.1111/ibi.12118.

Wang, J., Chapman, D., Xu, J., Wang, Y., and Gu, B. (2018). Isotope niche dimension and trophic overlap between bigheaded carps and native filterfeeding fish in the lower Missouri River, USA. PLOS ONE 13, e0197584. doi:10.1371/journal.pone.0197584.

Wassenaar, L. I., and Hobson, K. A. (2003). Comparative equilibration and online technique for determination of non-exchangeable hydrogen of keratins for use in animal migration studies. Isotopes Environ. Health Stud. 39, 211-217. doi:10.1080/1025601031000096781.

Wassenaar, L. I., and Hobson, K. A. (2006). Stable-hydrogen isotope heterogeneity in keratinous materials: mass spectrometry and migratory wildlife tissue subsampling strategies. Rapid Commun. Mass Spectrom. 20, 2505-2510. doi:10.1002/rcm.2626.

Yohannes, E., Hobson, K. A., and Pearson, D. J. (2007). Feather stable-isotope profiles reveal stopover habitat selection and site fidelity in nine migratory species moving through sub-Saharan Africa: Feather stable-isotope profiles reveal stopover habitat selection. J. Avian Biol. 38, 347-355. doi:10.1111/j.2007.0908-8857.03927.x.

Zurell, D., Gallien, L., Graham, C. H., and Zimmermann, N. E. (2018). Do longdistance migratory birds track their niche through seasons? J. Biogeogr. 45, 1459-1468. doi:10.1111/jbi.13351. 


\section{Figures}

800

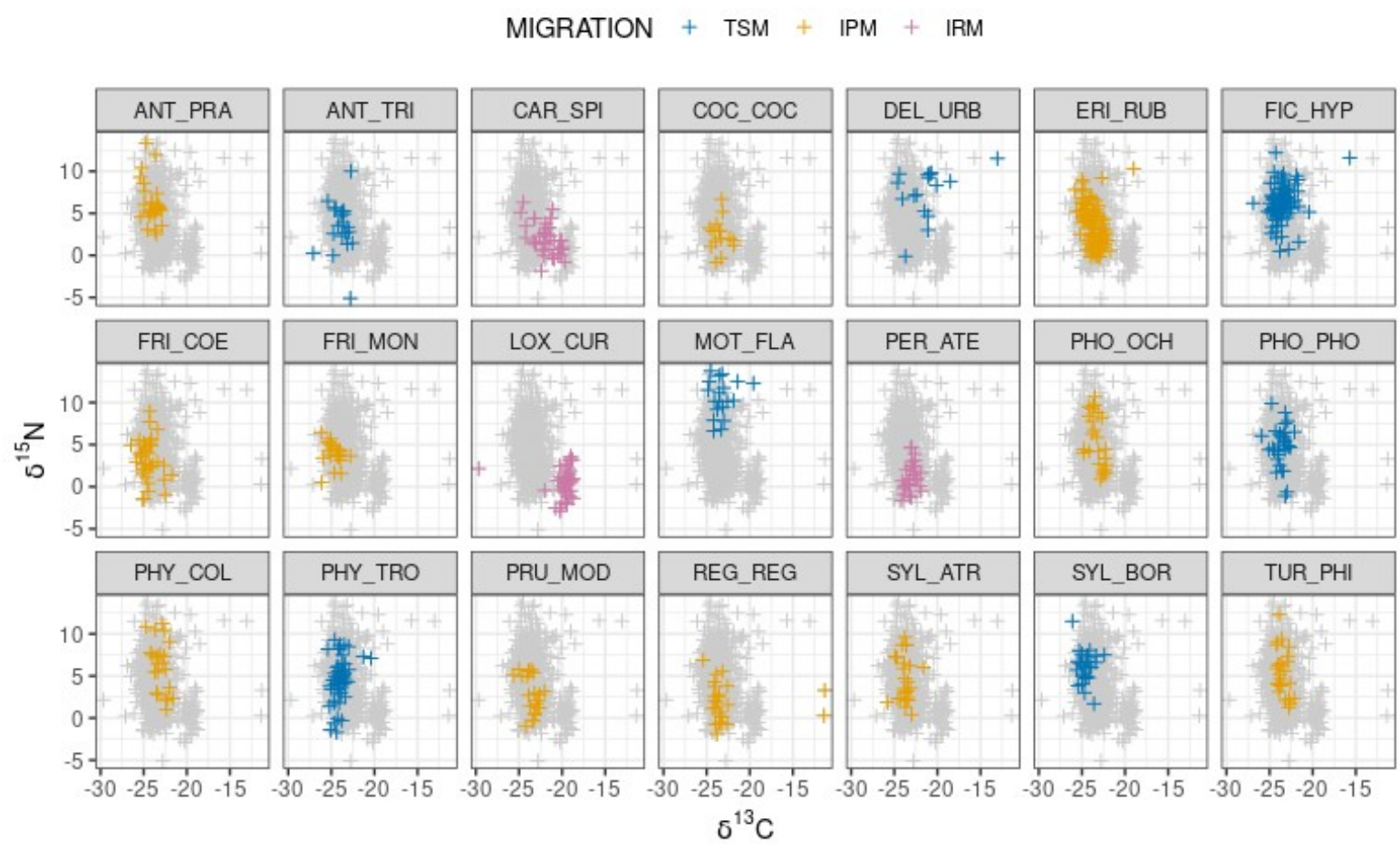

Fig. 1 - Distribution of each species and individuals over the $\delta^{13} \mathrm{C}-\delta^{15} \mathrm{~N}$ isotope space defining the dietary niche. Grey crosses in the background show the overall space occupied by the species (acronyms provided in Tab.S1). TSM=Trans-Saharan migrants; IPM=Intra-Palearctic migrants; 805 IRM=Irruptive migrants 
MIGRATION + TSM + IPM + IRM
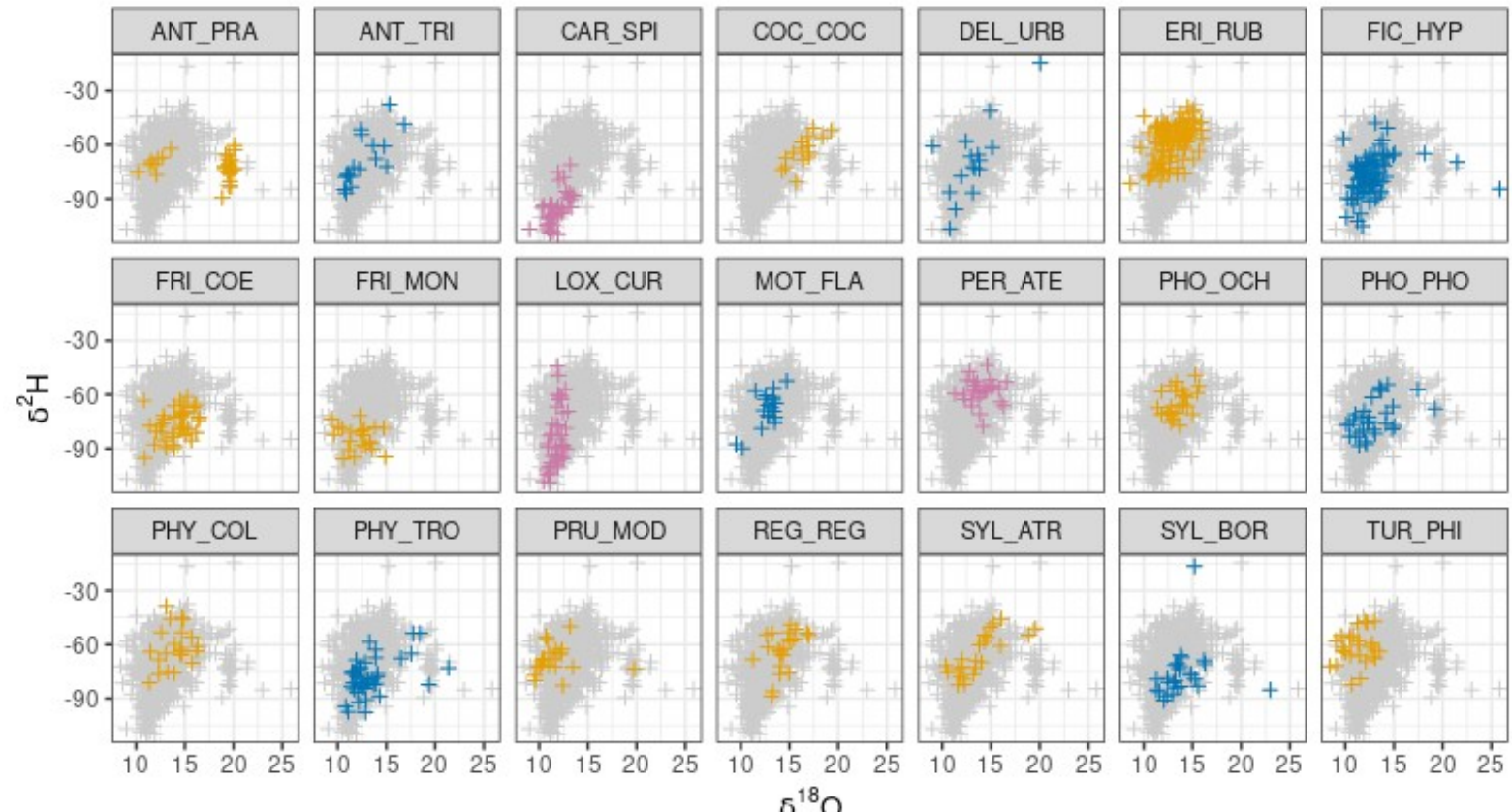

Fig. 2 - Distribution of each species and individuals over the $\delta^{2} \mathrm{H}-\delta^{18} \mathrm{O}$ isotope space defining the spatial origin niche. Acronyms as in Fig.1

825

830 


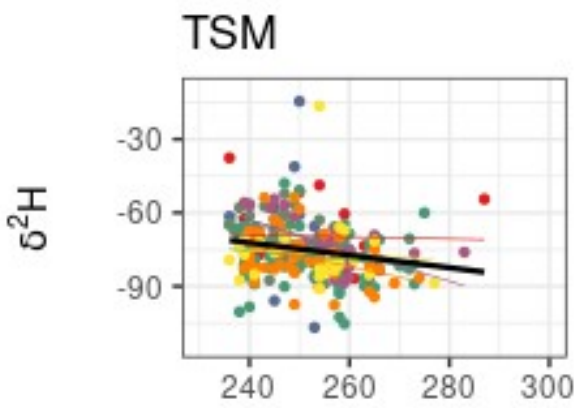

IPM
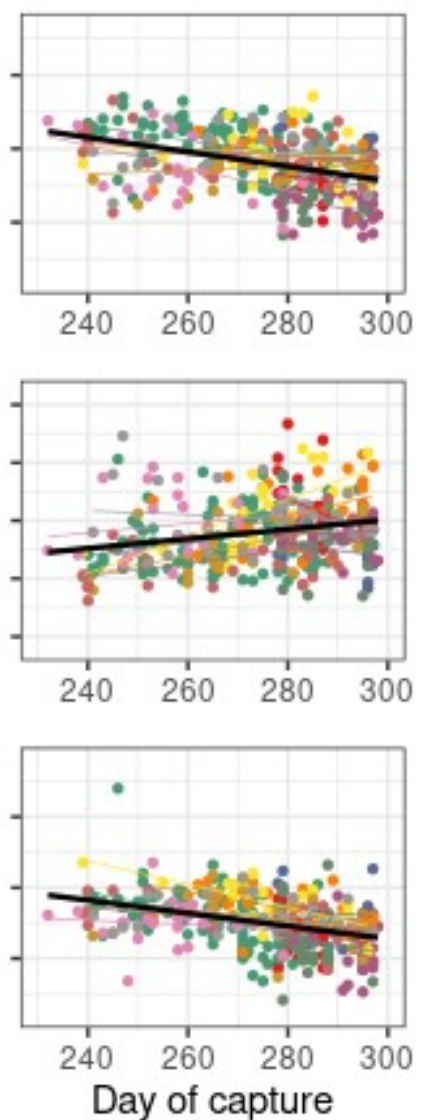

IRM
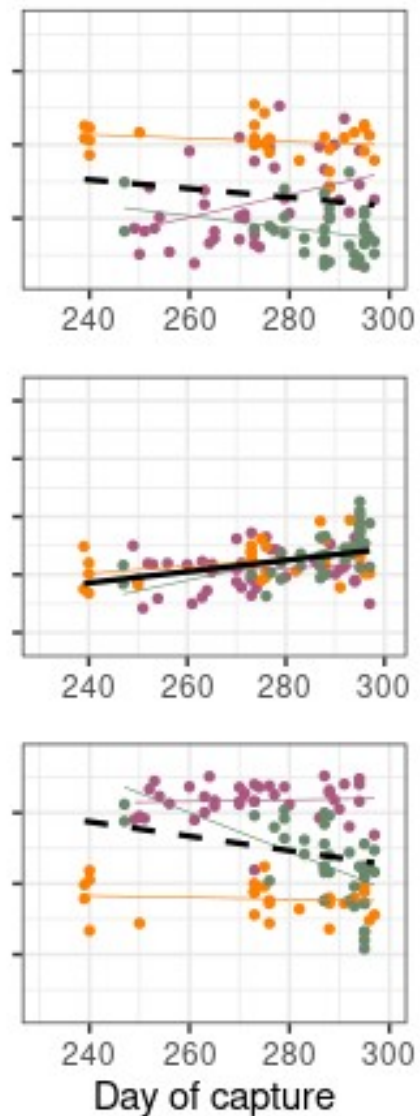

Fig. 3 - Seasonal trends in $\delta^{2} \mathrm{H}, \delta^{15} \mathrm{~N}$ and $\delta^{13} \mathrm{C}$ values for the TSM, IPM and IRM groups. Black fit line indicates overall trend (dashed line $=N S$ ), while individual species trends are shown in different

845 colours. 

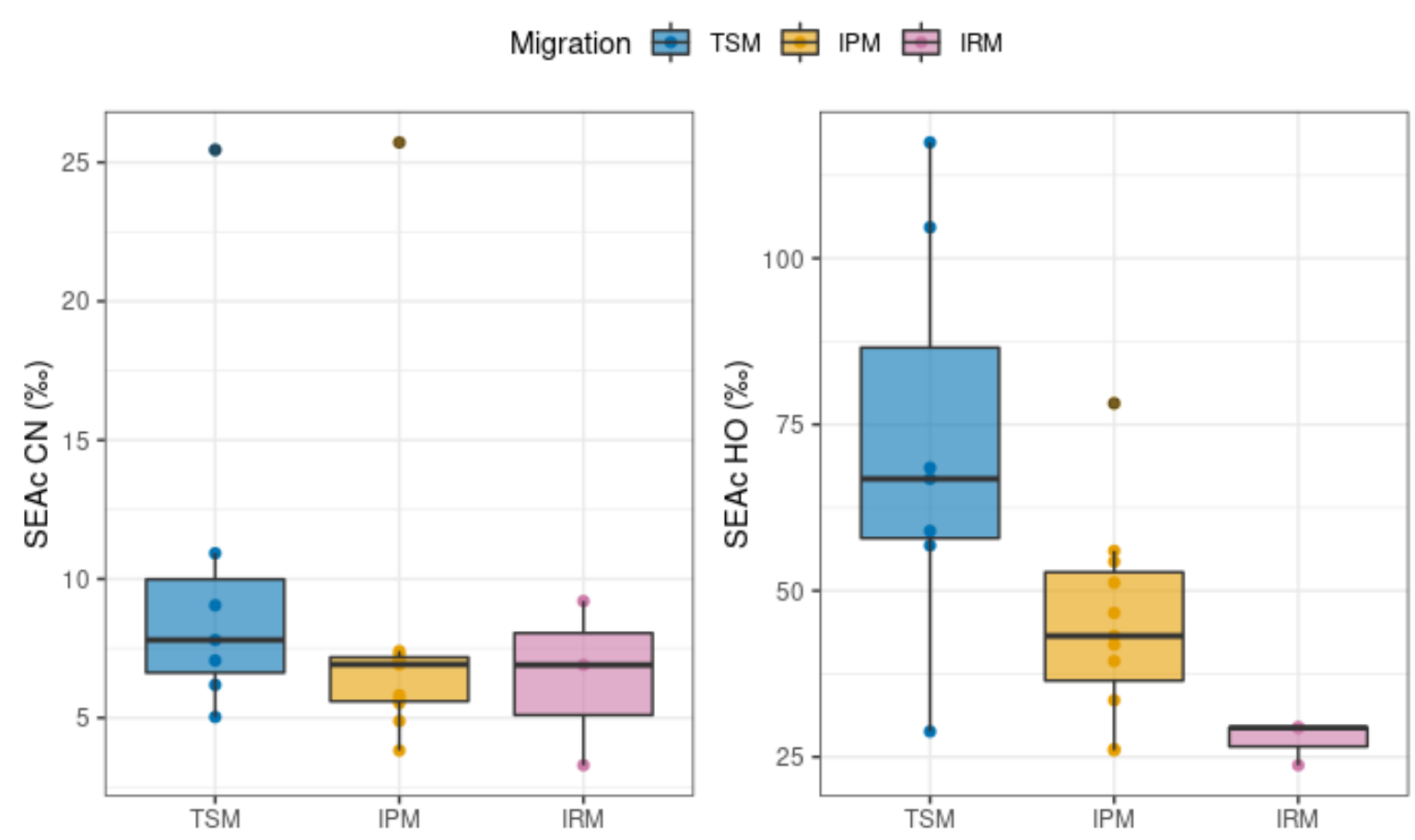

860

Fig. 4 - Comparison of the average species dietary and origin isotopic niche breadth among migratory groups.

865 


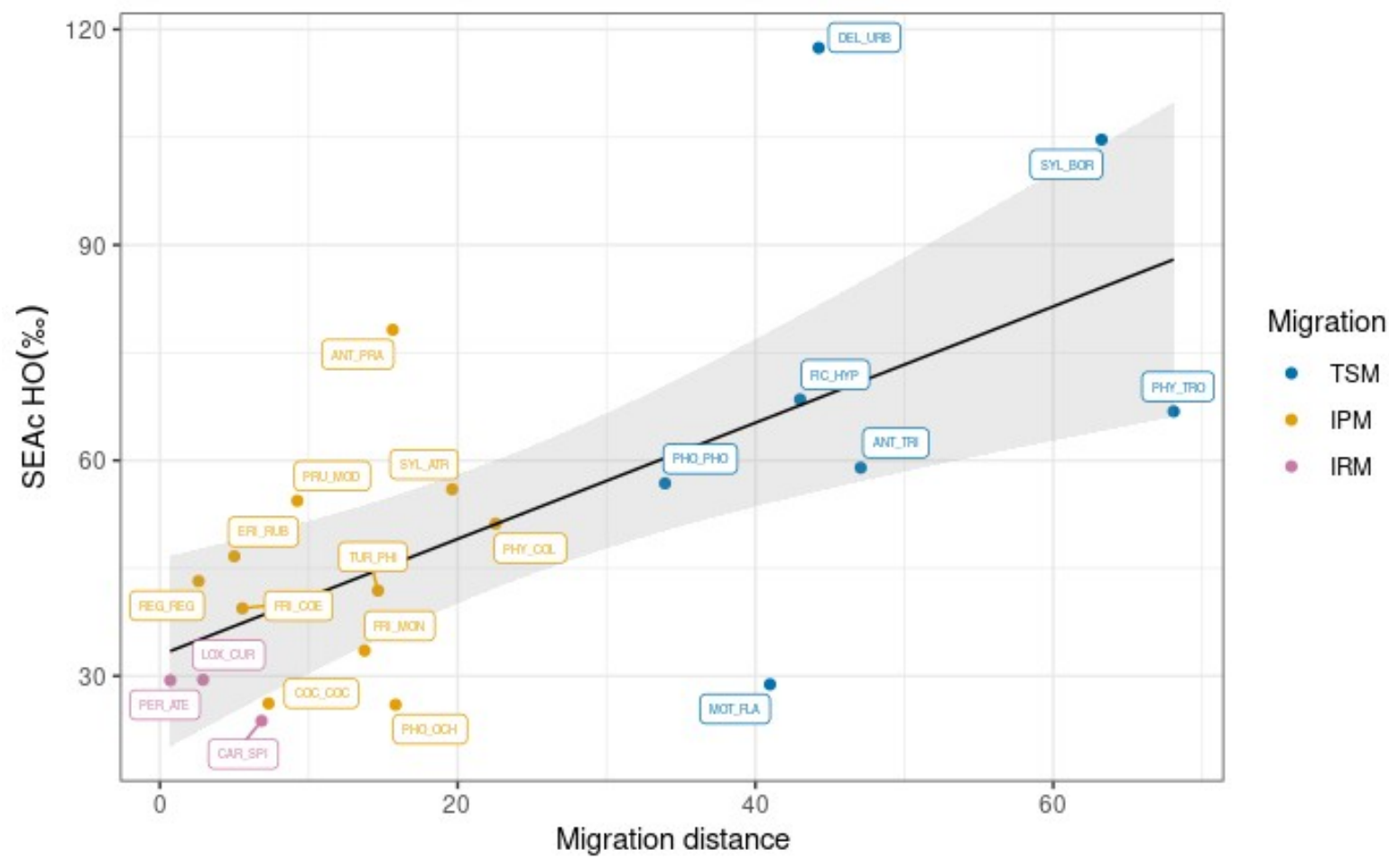

Fig.5 - Relationship between species origin niche breadth and migration distance, defined as the 885 latitudinal distance between the centroid of the breeding and wintering ranges. Species identity is labelled. 

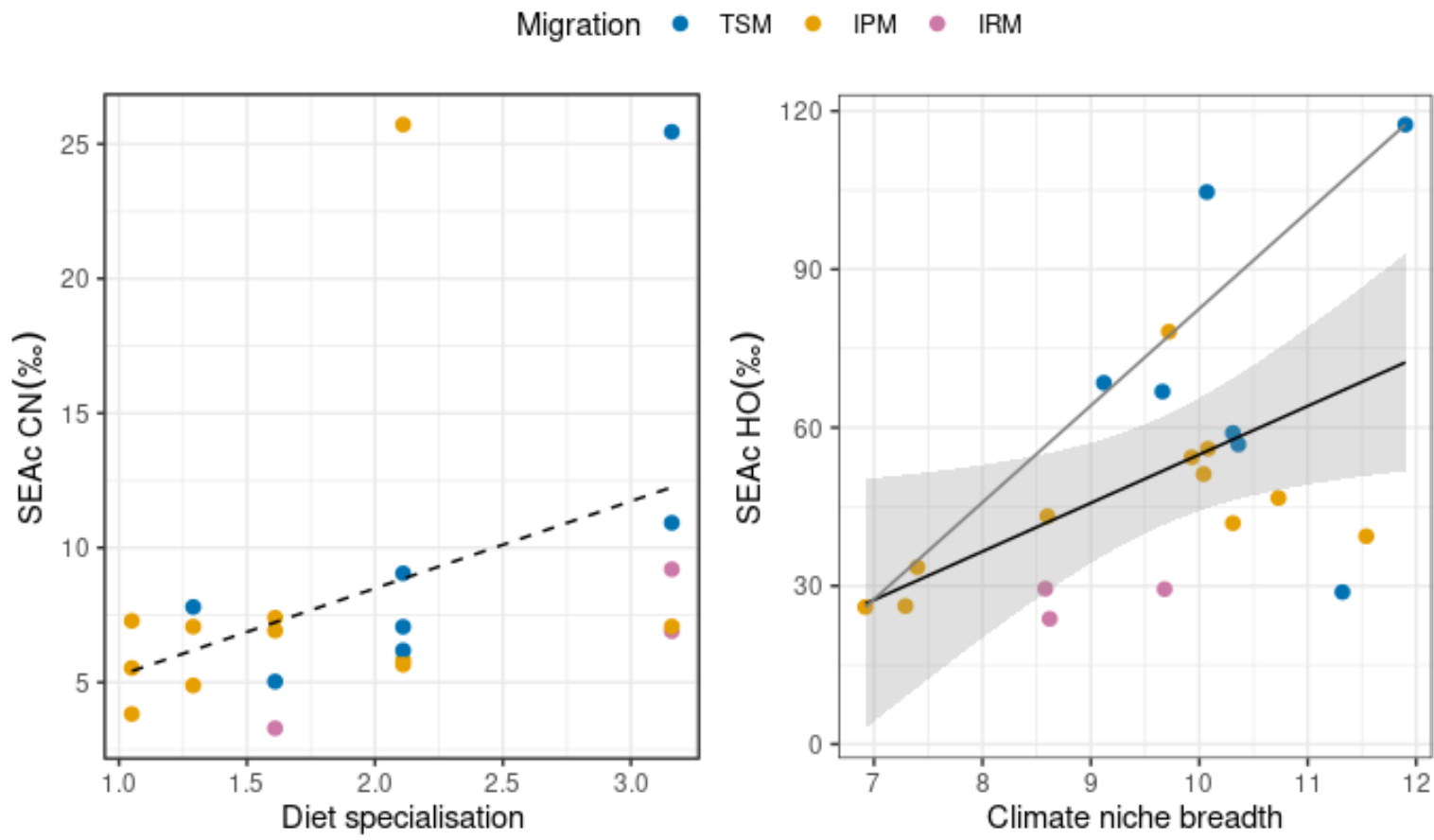

Fig. 6 -Relation between empirical dietary and origin isotopic niche breadth with literature-derived niche parameters (from Reif et al 2016). Dashed line $=N S$ relation; tick black line $=$ significant regression fit; thin grey line $=$ significant quantile regression fit at $q=0.8$ 
bioRxiv preprint doi: https://doi.org/10.1101/2021.04.27.441573; this version posted April 28, 2021. The copyright holder for this preprint (which was not certified by peer review) is the author/funder. All rights reserved. No reuse allowed without permission.

920

925 